\section{HOTEL RESERVATION FORM 1985 MRS FALL MEETING \\ December 2-7, 1985}

- Symposia will be held at the Boston Marriot Hotel/Copley Place and the Westin Hotel. The hotels are connected by a covered walkway. The locations of symposia and other activities are summarized in the activities locator at the back of this brochure.

- All hotel reservation cards are to be sent to the Boston Marriot HotelCopley Place, regandless of whether the Marriot or the Westin is the preferred hotel. If your first choice is not available, your reservation will automatically be placed with the other hotel as long as space is available.

- If you telephone your reservation, you must mention the Materials Research Society meeting to receive the special rates.

- Roum rates are as follows. Please clrele preferred hotel and type of room desired:

The Westin HoreVCopley Place (800) 228-3000 Single* Double*

Boston MarriotuCopley Place (800) 228-9290 "plus Massachusetts hotel tax

$\$ 93 \quad \$ 107$

$586 \quad 597$

Name

Institution

Address

City State

Country Zip Code

Telephone (

Arrival Date Time

Departure Date

Number of Adults (additional charge for more than 2 adults).

- Reservations will be held until 6 p.m. only, unless guaranteed by one of the following credit cards (please circle appropriate gurantee):

AX (American Express

Visa (Visa)

MC (Master Card) DC (Diners Club)

Credit Card Number:

Expiration Date

Sigmature

- Check-in time: after 4 p.m., check-out time: before 1 p.m.

\section{PREREGISTRATION FORM \\ MATERIALS RESEARCH SOCIETY 1935 FALL MEETING}

One registrant per card. Please print or type.

Name

Lax Fira Name / M

Institution

Address

City State

Zip Code Country

Telephone (

This address is: $\square$ Institution $\square$ Home

\section{SYMPOSIUM INTEREST}

(Please check at least one)

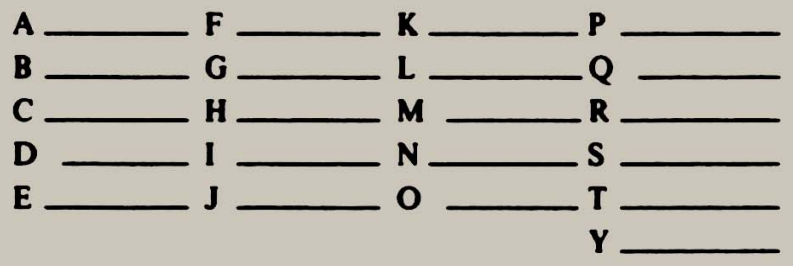

Fall Meeting Preregintration Feec:

Please check regiatntion category and enter fee on line below.

口 SISS Regular

口 S4S Student

Reginturation fee:

$\mathbf{S}$

Publications Order (from other side):

S

Total Paymeat S

Make check (on U.S. bank only) payable to the MATERIALS RESEARCH SOCIETY and send with this form to:

Maverials Research Society Headquariers. 1985 Fall Mecting Registration 9800 Mck night Road, Suive 327 Pinsburgh, PA 15237, U.S.A.

\section{- Deadilne November 1, 1935}

Late registration and at-meeting registration fees will be S170 Regular and S5S Student.

Preregistration cards received without payment will be charged at-meeting rates. 


\section{PROCEEDINGS ORDERS \\ 1985 FALL MEETING}

Symposia A, B, C, E, G, H, I, J, K, L, P, Q, R, S, T, and Y plan to publish proceedings, which will be available after the meaing. In addition, Symposia D, N, and $\mathrm{O}$ will publish extended abstracts booklets, which will be available at the meeting. To receive copies of proceedings volumes or extended abstracts booklets, fill out the form below and enter total price both here and on the other side. Please note: These prices apply only to meeting registrants and MRS members. Nonmembers should contact MRS headquarters for prices and ordering information.

\section{Conference Proceedings}

A Beam-Solid Interaction

B Rapad Thermal Processing

C SOl/TFT Technology

E Thin Fulms

G Buomedical Materuals

H Layered Structures

I Phase Transituons

J Rapudly Solidified Alloys

K O, C. H. $\mathrm{N}$ in Silicon

L Defect Propenies

$P$ Defects in Glasses

Q Transmission Electron Micr

R Computer Descr. of Mat's

S Cement-Based Composiles

T Fly Ash and Coal Conv.

$Y$ Materials Education

Extended Abstracts

D Beam-Induced Processes

$N$ Fraclals

O Nonlinear Optical Matenals

$$
\begin{aligned}
& \text { NUMBER } \\
& \text { OF } \\
& \text { COPIES } \\
&
\end{aligned}
$$

$\$ 32 \times-5$

$\$ 30 \times-=\$$

$\$ 32 \times$

$\$ 39 \times-5$

$\$ 33 \times-5$

$\$ 34 \times-=\$$

$\$ 32 \times-=\$$

$\$ 28 \times \square=5$

$\$ 32 \times-=\$$

$533 \times-5$

$528 \times \square=5$

$533 \times-=\$$

S30 $\times 2=\$$

S24 $\times$ -

$524 \times-5$

$524 \times \square=S$

$55 \times-=5$

$\begin{array}{lll}55 \times- & 5 \\ \text { S } 5 \times 2 & =5\end{array}$

PLEASE SIGN AND DATE YOUR ORDER:

Signature

Date

Enter this total in the space provided on the other side

\section{SHIPPING ADDRESS}

If shipping address is same as address on Registration Form, simply enier "SAME" below. Otherwise, fill in address below to which proceedings volumes are to be shipped and check address carefully for correctness.

Name

Institution

Address

City State

Country Zip Code

Telephone (

This address is: $\square$ Institution $\square$ Home 


\section{PREREGISTRATION FORM} 1985 MRS SHORT COURSES

Friday - Saturday, December 6-7, 1985

I wish to register for (please check):

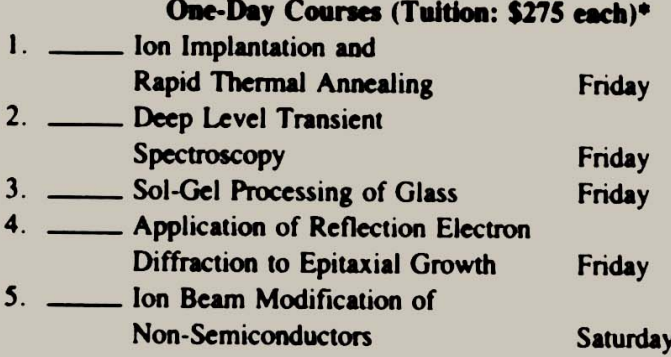

NOTE: Participants may attend a one-day course on Friday and the one-day course on Saturday at the rate for a two-day course.

\section{Two-Day Courses (Tultion: S435 each)*}

6. Surface and Thin Film Analysis

Friday and Saturday

7. Liquid Phase Epitaxy Techniques

Friday and Saturday

8. Vapor Phase Epitaxy

9. Molecular Beam Epitaxy

Friday and Saturday

10. _ Vacuum Technology

Friday and Saturday

11. Materials Aspects of Silicon Devices

12. El_ectronic Properties of Amorphous Semiconductors

13. Processing-MicrostructureMechanical Property Relationships in Metals

14. Films and Coatings for Engineering Applications

Friday and Saturday

Friday and Saturday

Friday and Saturday

Friday and Saturday

Friday and Saturday

-DEADLINE FOR PREREGISTRATION: November 1. 1985

Later registrations and at-meeting registrations: \$300 for one-day courses; $\mathbf{S 4 0}$ for two-day courses.

SHORT COURSE FEE \$

Name

Institution

Address

City State

Country Zip Code

Telephone

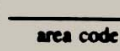

This address is. $\square$ Insuteurion

\section{$\square$ Home}

Make check (on U.S. bank only) payable to the MATERIALS RESEARCH SOCIETY and send with this form to:

Materials Research Society Headquarters. Shor Course Registration. 9800 McKnight Road, Suite 327. Pittsburgh, PA 15237, U.S.A.

CANCELLATION POLICY: Short course registration cancellations received before November 22 will be refunded less service charge of 510 . No refunds will be made for cancellations received after November 22 or to persons who do not anend but fail to notify the Society.

The Materials Research Society reserves the right to cancel a short course if factors beyond our control make it impractical, In such an event, registrants will be notified as quickly as possible and full refund of tuition will be made. 


\section{REGISTER EARLY}

- Short Course Preregistration

- Meeting Preregistration

- Hotel Reservations

Preregistration Deadline: November 1, 1985

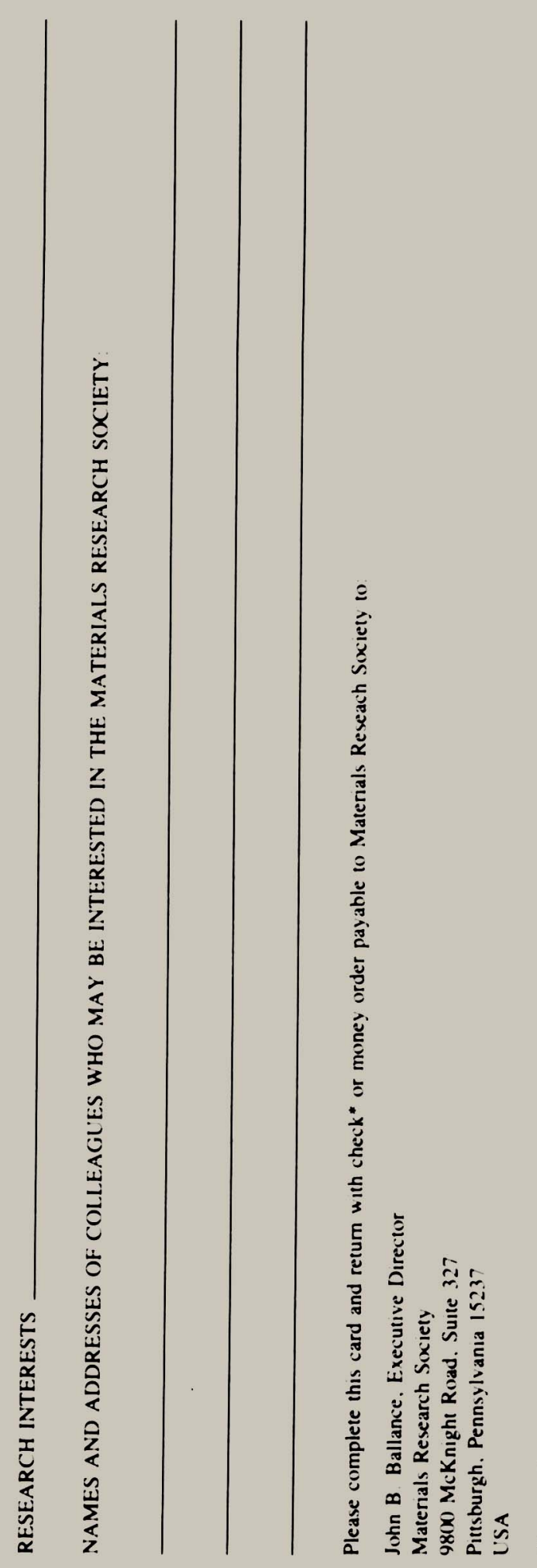


will span polymer-polymer interdiffusion, diffusion in polymers, polymeric metals and semiconductors, energy/excitation transport in polymers, photoeffects in polymers, polymers in micro-imaging, ion beam effects in polymers, radiation effects in polymers, field-induced effects in polymers. Invited speaker include: J. Klein, P. G. deGennes, H. Yu, S. F. Edwards, B. Christ, M. Tirrell, B. A. Smith, E. D. von Meerwall, H. B. Hopfenberg, A. G. MacDiarmid, T. J. Marks, G. L. Baker, M. A. Ratner, A. J. Heeger, R. L. Elsenbaumer, M. Kertesz, G. Harbeke, H. A. Pohl, L. W. Shacklette, T. A. Skotheim, J. B. Lando, H. Sasabe, Curtis W. Frank, Stephen E. Webber, S. Etemad, P. M. Borsenberger, R. Svinivasan, Gary N. Taylor, G. Willson, G. Foti, R. S. Potember, S. Triphaty, ]. I. Scheinbeim.

\section{Biomedical Materials \\ (Symposium G) \\ December 3-6 (Tuesday-Friday) \\ Chairs: M. F. Nichols, University of Missouri; J. M. Williams, Oak Ridge \\ National Laboratory; W. Zingg, \\ University of Toronto}

Approximately 55 papers and panel discussions will explore cardiovascular materials, opthalmic biomaterials, reconstruction materials for bone and teeth, materials for orthopaedics, biomaterials for electrodes, novel materials and techniques, materials problems in simulation and practice, science and technology of biomaterials. Invited speakers include: Allan S. Hoffman, H. K. Yasuda, J. Michael Lee, Eugene P. Goldberg, Larry L. Hench, D. F. Williams, J. E. Lemons, John T. Scales, F. T. Hambrecht, D. F. Gibbons.

\section{Layered Structures and Epitaxy}

(Symposium $\mathrm{H}$ )

December 2-6 (Tuesday-Friday)

Chairs: J. M. Gibson, AT\&T Bell

Laboratories; G. C. Osbourn, Sandia

National Laboratories; R. M. Tromp, IBM Research Center

Approximately 87 oral and poster papers will examine epitaxial semiconductor films, surfaces and ultrathin films, epitaxial silicides, quantum wells, strained layer superlattices, Ge/Si and non-crystalline superlattices, metal superlattices. Invited speakers include: R. C. Pond, K. Takayanagi, E. J. van Loenen, G. A. Prinz, R. T. Tung, P. S. Ho, L. L. Chang, P. Petroff, F. Capasso, J. N. Schulman, L. Dawson, T. Picraux, E. Kasper, E. Spiller, T. Tsakalakos.

\section{Phase Transitions in Condensed} Systems-Experiments and Theory (Symposium I)

A Symposium in Honor of Professor David Turnbull

December 5-6 (Thursday-Friday)
Chairs: G. S. Cargill III, IBM Corporation; F. Spaepen, Harvard University, K. N. Tu, IBM Research

Approximately 37 papers will explore nucleation, liquids, glasses, and glass formation; diffusion and defects; crystal growth and solid state transitions. Invited speakers include: John W. Cahn, F. Spaepen, D. Lazarus, M. E. Glicksman.

\section{Rapidly Solidified Alloys and Their} Mechanical and Magnetic Properties (Symposium J)

December 2-4 (Monday-Wednesday)

Chairs: B. C. Giessen, Barnett Institute;

D. E. Polk, Office of Naval Research; A. I.

Taub, G. E. Corporate Research and

Development

Approximately 73 oral and poster presentations will address fundamentals and processing; structure and properties of amorphous, quasicrystalline and metastable crystalline alloys; rapidly solidified alloys and their mechanical properties; magnetic properties of rapidly solidified alloys. Invited speakers include: B. L. Mordike, W. L. Johnson, R. Hasegawa, R. J. Schaefer, F. H. Froes, J. R. Pickens, A. I. Taub, H. Jones, R. C. O’Handley, G. C. Hadipanayis.

\section{Oxygen, Carbon, Hydrogen, and} Nitrogen in Crystalline Silicon (Symposium K)

December 2-5 (Monday-Thursday)

Chairs: J. W. Corbett, SUNY at Albany; J. C. Mikkelsen, Jr., Xerox Corporation; S. J. Pearton, AT\&T Bell Laboratories; S. J.
Pennycook, Oak Ridge National Laboratory

Approximately 63 oral and poster presentations will address oxygen precipitation thermal donors, bulk oxygen behavior and related defects, carbon in silicon, hydrogen in silicon, nitrogen in silicon. Invited speakers include: A. Bourret, T. Y. Tan, S. M. Hu, L. C. Kimerling, M. Stavola, J. M. Spaeth, P. Wagner, L. C. Snyder, J. C. Mikkelsen, Jr., J. L. Lindstrom, A. Ourmazd, K. Sumino, R. C. Newman, U. Gosele, S. J. Pearton, T. Abe, H. J. Stein, R. J. Jaccodine.

Defect Properties and Processing of High-Technology Nonmetallic Materials (Symposium L)

December 2-4 (Monday-Wednesday)

Chairs: Y. Chen, Oak Ridge National

Laboratory; W. D. Kingery,

Massachusetts Institute of Technology;

R. J. Stokes, Honeywell, Inc.

Approximately 74 oral and poster papers will discuss advanced processing; lattice defects, interfaces and surfaces; surface modification; microwave processing; optical materials; mechanical properties. Invited speakers include: J. B. Wachtman, H. K. Bowen, A. G. Evans, J. H. Harding, C. B. Carter, J. Narayan, Wayne R. Tinga, Rustum Roy, M. P. Harmer, Richard C. Powell, R. Holman, Tadashi Miyashita, A. H. Heuer, F. F. Lange.

Oxides, Zeolites and Clays in Catalysis (Symposium M)

December 2-4 (Monday-Wednesday)

Chairs: D. E. W. Vaughan, Exxon

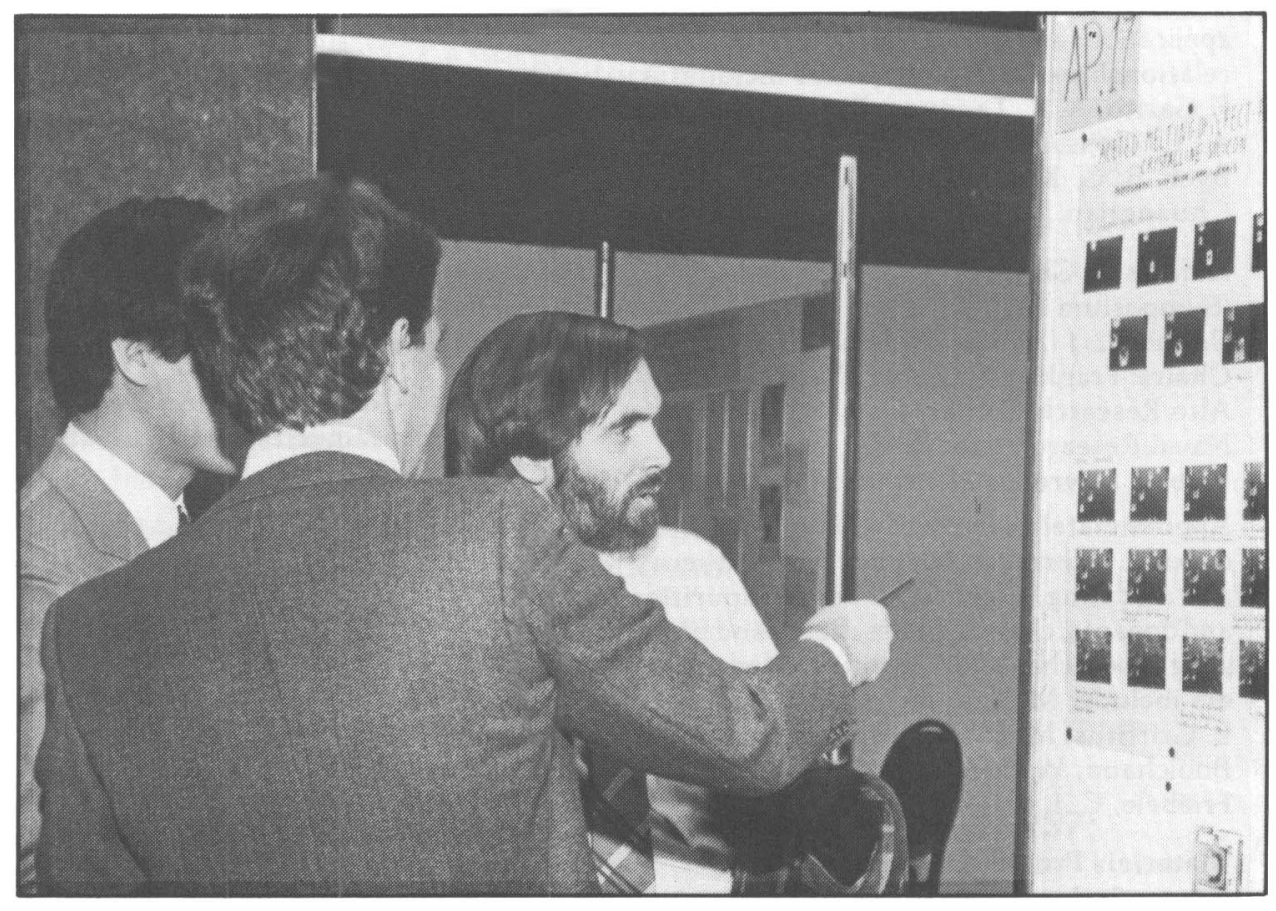

Poster sessions will be open Tuesday through Thursday for registrants to browse and hold informal discussions with colleagues. 
Research and Engineering; A. W. Sleight, E. I. du Pont de Nemours

Approximately 33 papers will investigate catalyst characterization and synthesis of oxides and hydroxides, synthesis and characterization of clays and pillared clays, clay and pillared clay catalysts, zeolite synthesis and characterization, zeolite structural and catalytic characterization. Invited speakers include: John M. Thomas, F. S. Stone, JiXiang Wang, A Schutz, R. A. van Santen, G. T. Kerr, D. Barthomeuf.

\section{Fractal Aspects of Materials}

(Symposium N)

December 2-4 (Monday-Wednesday)

Chairs: R. B. Laibowitz, IBM Research

Center; B. B. Mandelbrot, Harvard

University; D. E. Passoja, Passoja Inc

Approximately 38 papers and panel discussions will span various topics dealing with the charaterization and application of fractals. Invited speakers include: R. F. Voss, D. W. Schaefer, H. J. Wiesmann, J. Klafter, P. W. Schmidt, B. Sapoval, Y. Termonia, D. A. Weitz, K. Kubik, B. B. Mandelbrot, P. G. deGennes, R. L. Orbach, A. P. Thomas, M. Maurette, R. Kopelman, Y. Gefen, L. M. Sander, R. Messier.

\section{Nonlinear Optical Materials}

(Symposium O)

December 4-6 (Wednesday-Friday)

Chairs: A. M. Glass, AT\&T Bell

Laboratories; D. A. B. Miller, AT\& T Bell

Laboratories; C. L. Tang, Cornell

University

Approximately 43 papers will discuss polymers, photorefractive materials, semiconductors and microstructures, organics, applications and growth, structure-property relationships. Invited speakers include: A. F. Garito, A. R. Tanguay, R. W. Hellwarth, A. C. Gossard, D. Ricard, J. Zyss, R. L. Byer, B. G. Kushner, W. C. Egbert, Chen Chuangtian.

\section{Defects in Glasses}

(Symposium P)

December 2-4 (Monday-Wednesday)

Chairs: Frank L. Galeener, Xerox Palo Alto Research Center; David L. Griscom, Naval Research Laboratory; Marvin J. Weber, Lawrence Livermore Laboratory

Approximately 44 papers will explore silicon dioxide, intermediate range order, theory and modeling, short range order, inpurities and dopants, chalcogenides, fibers and films, gel glasses, characterization. Invited speak ers include: M. Kastner, A. H. Edwards, J E. Griffiths, M. F. Thorpe, S. A. Brawer, P Boolchand, W. B. Sibley, P. C. Taylor, E. J. Friebele, C. J. Brinker.

\section{Materials Problem Solving with the} Transmission Electron Microscope (Symposium Q)
December 2-4 (Monday-Wednesday)

Chairs: L. W. Hobbs, Massachusetts

Institute of Technology; K. H.

Westmacott, Lawrence Berkeley

Laboratory; D. B. Williams, Lehigh

University

Approximately 59 papers will examine electron microscopy of electronic materials, analytical electron microscopy, precipitate and phase analysis, transformations and amorphization, catalysts and ceramics. Invited speakers include: Janet $M$. Brown, $T$. Sands, Fernando A. Ponce, P. S. Sklad, A. J. Garrett-Reed, M. Disko, J. A. Eades, J. C. H. Spence, A. D. Romig, M. Raghavan, U. Dahmen, W. Kesternich, J. R. Michael, A. R. Pelton, M. M. J. Treacy, C. E. Layman.

Computer-Based Microscopic Description of the Structure and Properties of Materials

(Symposium R)

December 4-6 (Wednesday-Friday)

Chairs: J. Broughton, SUNY-Stonybrook;

W. Krakow, IBM T. J. Watson Research

Center; S. T. Pantelides, IBM T. J.

Watson Research Center

Approximately 46 papers will discuss applications in metals, electronic materials, alloys, glasses, and polymers, and theoretical studies. Invited speakers include: B. Berne, A. J. Freeman, W. A. Goddard III, R. Car, D. L. Mills, J. Doll, W. Krakow, J. Hafner, A. Angell, M. L. Cohen, O. K. Anderson, W. Hoover, V. Vitek, K. C. Pandey, L. Bakker, J. Eberhardt, K. A. Jackson, J. Haile, P. B. Allen, U. Landman.

\section{Cement-Based Composites: Strain Rate} Effects on Fracture

(Symposium S)

December 4-5 (Wednesday-Thursday)

Chairs: S. Mindess, University of British

Columbia; S. P. Shah, Northwestern

University

Approximately 24 papers will explore strainrate effects, cracking and strength at varying strain rates, dynamic effects. Invited speakers include: F. H. Wittmann, S. P. Shah, H. W. Reinhardt, L. E. Malvern.

Fly Ash and Coal Conversion ByProducts: Characterization, Utilization and Disposal II

(Symposium T)

December 2-4 (Monday-Wednesday)

Chairs: G. J. McCarthy, North Dakota

State University; D. M. Roy,

Pennsylvania State University

Approximately 45 papers will span utilization, characterization and reactions, fly ash standards and data centers, modeling of properties, environmental considerations, characterization and utilization. Invited speakers include: G. M. Idorn, M. A. Mearing, R. B. Finkelman, R. C. Joshi, I. P. Murarka, T. Anthony.

\section{Frontiers in Materials Research}

(Symposium $X$ )

December 2-5 (Monday-Thursday)

Chair: Rustum Roy, Pennsylvania State University

Five sessions of "Tutorial Reviews for the Non-Specialist" will cover aspects of clays and zeolites, amorphous metals, thin films, semiconductors, ceramic composites, semiconducting and metallic polymers, materials for lasers. Speakers include: J. M. Thomas, Don E. Polk C. A. Evans, J. Narayan, M. S. Newkirk, M. K. Aghajanian, R. W. Cahn, R. F. Messier, Alan Heeger, A. Mooradian.

\section{Frontiers in Materials Education}

(Symposium Y)

December 3-4 (Tuesday-Wednesday)

Chairs: G. L. Liedl, Purdue University; L.

W. Hobbs, Massachusetts Institute of Technology

Approximately 23 papers will discuss materials education - philosophy and future, industry-government interactions, ceramics, polymers, and problem areas, crossdiscipline education. Invited speakers include: M. Cohen, I. M. Bernstein, M. C Flemings, R. Roy, J. J. Harwood, P. Chaudhari, S. Hecker, E. L. Thomas, D. W. Ready, H. Marcus.

\section{FALL MEETING TIMETABLE}

REGISTRATION HOURS

(Fourth Floor)

Sunday: 4:00 p.m.-7:00 p.m

Monday: $7: 00$ a.m. $-9: 00$ p.m

Tuesday-Thursday: 7:30 a.m.-5:00 p.m

Friday: $7: 30$ a.m.-noon

POSTER SESSION HOURS:

(See session locations in Preliminary and Final Programs)

Tuesday-Thursday: 7:00 a.m.-10:00 p.m.

EQUIPMENT EXHIBIT HOURS

(Exhibit Hall)

Tuesday-Wednesday: 9:00a.m.-5:00 p.m. Thursday: 9:00 a.m. $-2: 00$ p.m.

JOB PLACEMENT CENTER HOURS

Tuesday-Thursday: 9:00 a.m.-5:00 p.m. Fee: $\$ 5.00$ for employment candidates (complete Job Placement Form in this issue)

$\$ 60.00$ for employers

VON HIPPEL AWARD AND

LECTURE:

(Grand Ballroom)

Monday 6:30 p.m.

PLENARY SESSION

(Grand Ballroom)

Wednesday: $5: 45$ p.m.-7:00 p.m

"Materials for SDI"
Gerald Yonas 


\section{SHORT COURSES \\ On \\ ADVANCED MATERIALS RESEARCH TECHNIQUES}

Sponsored by the Materials Research Society in conjunction with the 1985 Fall Meeting, Boston, Massachusetts.

Make plans now to round out your week in Boston at the MRS Fall Meeting by attending an MRS short course. Look for details and registration information in the mail and register early.

Friday, December 6, (One-Day Courses)

Ion Implantation and Rapid Thermal Annealing

Instructor: T. E. Seidel, J. C. Schumaker Co.

Deep Level Transient Spectroscopy

Instructor: C. E. Barnes, Aerospace Corporation

Sol-Gel Processing of Glass

Instructor: C. Jeffrey Brinker, Sandia National Laboratories

Applications of Reflection Electron Diffraction to Epitaxial Growth

Instructor: P. I. Cohen, University of Mirinesota

Saturday, December 7 (One-Day Course)

Ion Beam Modification of Non-Semiconductors

Instructor: J. K. Hirvonen, SPIRE, Inc.

Friday-Saturday, December 6-7 (Two-Day.Courses)

Surface and Thin Film Analysis

Instructors: Leonard C. Feldman, AT\&T Bell Laboratories James W. Mayer, Cornell University

Liquid Phase Epitaxy Techniques

Instructor: L. R. Dawson, Sandia National Laboratories

Vapor Phase Epitaxy

Instructors: Herbert M. Cox, Bell Communications Research

P. D. Dapkus, University of Southern California

Molecular Beam Epitaxy

Instructor: Gary W. Wicks, Cornell University

Vacuum Technology

Instructor: Mars H. Hablanian, Varian Vacuum Division

Materials Aspects of Silicon Devices

Instructors: Subhash Mahajan, Carnegie-Mellon University

K. S. SreeHarsha, San Jose State University

Electronic Properties of Amorphous Semiconductors

Instructor: David Adler, Massachusetts Institute of Technology

Processing-Microstructure-Mechanical Property Relationships in Metals

Instructor: Kenneth H. Eckelmeyer, Sandia National Laboratories

Films and Coatings for Engineering Applications

Instructor: Don Mattox, Sandia National Laboratories

The MRS Short Course Program is an activity of the MRS Education Committee.

Materials Research Society, 9800 McKnight Road, Suite 327, Pittsburgh, PA 15237; telephone (412) 367-3003. 


\section{MRS CORPORATE PARTICIPATION}

\section{An investment in excellence of advanced materials technology}

Nearly 100 organizations worldwide support the educational activities of the Materials Research Society by participating as Corporate Affiliates. The financial contributions and technical advice provided by Corporate Affiliates enables the Society to focus symposia, publications, and short courses toward a more thorough understanding of recent progress for the entire scientific community.

Corporate Affiliates will also enjoy the following benefits in 1986:

- One subscription each of MRS Bulletin and Journals of Materials Research.

- Advance consultation on topical program content and opportunity to meet with Society officers on topics of mutual concern.

- Free listing of employment opportunities in MRS Bulletin.

- Reduced rates on MRS symposia proceedings.

... and more.

For further information on the program, contact William Katz, General Electric/KAPL, P.O. Box 1072, Bldg., E1, Room 114C, Schenectady, NY 12301; telephone (518) 393-6611, ext. 7051.

\section{MRS Corporate Affiliates}

AG Associates

Air Products and Chemicals

ALCOA

Allied Corporation

American Microsystems, Inc.

AMOCO Corporation

Applied Materials

ARCO Metals Company

ARCO Solar, Inc.

AT\&T Bell Laboratories

AT\&T Technologies, Inc

Blake Industries, Inc.

Branson, IPC

Brimrose Corporation of America

Brush Wellman, Inc

Cabot Corporation

Cameca Instruments, Inc.

CEMCOM Research Associates

CILAS Alcatel

Combustion Engineering, Inc._-Power Systems

Denton Vacuum, Inc.

Drytek, Inc.

E. I. du Pont de Nemours \& Company

DynaVac

Eastman Kodak Company

Eaton Corporation

ELKEM Chemicals, Inc

Elsevier North-Holland

Energy Conversion Devices, Inc.

Engelhard Corporation

Charles Evans \& Associates

Exxon Research and Engineering Company

Ferranti, plc

GCA Corporation

(as of August 20, 1985)

General Electric Ceramics, Inc.

General Electric Company

General lonex Corporation

General Motors Research Laboratories

GTE Laboratories

Harshaw/Filtrol

Helionetics

High Voltage Engineering Europa B.V.

Hirst Research Centre

Hitachi Scientific Instruments

Hoya Optics, Inc.

Hughes Aircraft Company

imperial Chemical Industries, plc

Instruments SA, Inc.

International Business Machines Corporation

international Zeolite Association

JEOL USA

Jet Propulsion Laboratory

Lam Research

Lambda Physik

Lanxide Corporation

Lasertechnics

Lawrence Livermore National Laboratory

Leybold-Heraeus

LFE Corporation

Los Alamos National Laboratory

Lumonics

3M Company

Martin Marietta Laboratories

Materials Research Corporation

Microscience, Inc.

Monsanto

National Electrostatics Corporation
Newport Corporation

Perkin-Elmer

Philips Electronic Instruments, Inc

Plasma-Therm Systems, Inc.

Portland Cement Association

Quantronix Corporation

Questek, Inc.

Rockwell International

Sandia National Laboratories

Schlumberger-Doll Research

Schott Glass Technologies, Inc.

SEH America, Inc.

L. M. Simard, Inc.

SOHIO Chemicals \& Industrial Products

Solar Energy Research Institute

Solarex

Spire Corporation

Stauffer Chemical Company

Surface Science Laboratories, Inc.

Tamarack Scientific Co.

Tegal Corporation

TRW

Union Carbide Corporation

United Technologies Research Center

UOP

Varian/Extrion

VG Instruments, Inc.

W. R. Grace \& Company

Wacker Siltronic Corporation

Westinghouse Electric Corporation

Xerox Corporation

$X M R$

Zymet 


\title{
New and Recent Titles in Materials Science
}

Alumina: Processing, Properties and Applications E. Dörre and H. Hübner

Provides the first comprehensive presentation of alumina as a technical material, including details of production and processing methods. It describes the material behavior and underlying mechanisms from a materials science perspective and serves as a valuable reference to the physical and mechanical properties for researchers and manufacturers. In addition to a summary of current research, the book contains numerous examples of alumina applications in mechanical and electrical engineering, electronics, and medicine, as well as ideas and technical solutions for the creation of new products.

$1984 / 329 \mathrm{pp} .178$ illus./hardcover $\$ 36.00$

ISBN 0-387-13576-6

Materials Science and Engineering

New -

Electronic Properties of Materials:

An Introduction for Engineers

R.E. Hummel

Written specifically for materials and electrical engineers, this book covers the electrical, optical, magnetic, and thermal properties of materials and their applications. It stresses physical concepts rather than mathematical formalism to deliver a fundamental understanding of semiconductors, magnetic materials lasers, ceramics, and alloys. Plenty of practical applications, illustrations, and problems aid readers in gaining a realistic foundation in the electronic properties of materials.

$1985 / 320 \mathrm{pp}$./228 illus./hardcover $\$ 34.50$

ISBN 0-387-15631-3

\section{Ultrasonic Testing of Materials \\ Third Edition}

J. Krautkrämer and $\mathbf{H}$. Krautkrämer

Transiated from the Third German Edition by B.W. Zenzinger This classic in the field describes not only the fundamentals of the most important methods for nondestructive testing of materials, but also focuses on special problems in practical applications, the interpretation of response signals, and instrumentaton.

\section{3/667 pp./509 illus./hardcover $\$ 85.00$}

ISBN 0-387-11733-4

Electronic Properties of Doped Semiconductors

B.I. Shklovskii and A.L. Efros

Translated from the Russian by S. Luryi

Covers those phenomena on doped semiconductors that depend essentially on the disorder caused by randomly distributed space donors and acceptors, e.g. . Anderson localization, hopping conduction, metal non-metal transition due to compensation of impurities or due to an increase of the doping level, and optical phenomena related to the tails of the density of states.

$1984 / 388 \mathrm{pp} . / 106$ illus./hardcover $\$ 49.00$

ISBN 0-387-12995-2

Springer Series in Solid-State Sciences, Vol. 45

\section{Adhesives in Engineering Design}

W.A. Lees

This practical manual reflects extensive industrial experience in the use of adhesives for the assembly of mechanisms and structures and considers 'shop-floor' realities of manufacturing and use. Particular attention is paid to the nature, uses, and function of adhesives and the problems of selecting the most appropriate adhesive for a specific application. A special section leads readers through the steps of the selection process - this section is also available in corresponding EASel software for popular microcomputers.

$1984 / 147$ pp./46 illus./hardcover $\$ 28.00$

ISBN 0-387-15024-2

Published jointly with the Design Council, London, U.K.

New-

The Structure of Surfaces

M.A. Van Hove and S.Y. Tong

This book collects selected papers from the First International Conference on the Structure of Surfaces. The papers assess the status of surface structural determination and the relationship between surface or interface structures and physical or chemical properties. This includes solid and adsorbate-covered surfaces well-established and new surface-sensitive techniques, experiments, and theory.

$1985 / 435 \mathrm{pp}$. $/ 223$ illus./hardcover $\$ 49.00$

ISBN 0-387-15410-8

Springer Series in Surface Sciences, Vol. 2

\section{Landolt-Börnstein}

New Series

Numerical Data and Functional Relationships in Science and Technology

Editors in Chief: K.-H. Hellwege and O. Madelung

The New Series offers specialized, up-to-date, and reliable data in six classes of physical data: I. Nuclear and particle physics, II. Atomic and molecular physics, III. Crystal and solid state physics, IV. Macroscopic and technical properties of matter, $V$. Geophysics and space research, VI. Astronomy, astrophysics. and space research. Comprehensive indices for the New Series and the Sixth Edition are in preparation.

For more information or to order, please write to

Springer-Verlag New York, Inc.

Attn: Ken Quinn, Dept. S143

175 Fifth Avenue

New York, New York 10010

Orders from individuals must be prepaid and include $\$ 1.50$ for postage and handling. (New York and New Jersey residents please add sales tax.)

\section{Springer-Verlag}

\author{
New York
}

Berlin

Heidelberg

Vienna

Tokyo 